\title{
Olhando para trás: os dois nascimentos da doença de Alzheimer e a senilidade no Bra- sil $^{1}$
}

\author{
AnnetteLeibing ${ }^{2}$
}

\section{Resumo}

Este artigo tenta mostrar que a doença de Alzheimer é uma categoria médica que define a senilidade diferente das noções populares no Brasil, levantando a questão das conseqüências para as pessoas envolvidas com este mal. Favorecemos um olhar histórico para mostrar como dois momentos na história da doença de Alzheimer - os "dois nascimentos" - resultam do olhar científico de uma determinada época e sua maneira de produzir saberes.

Palavras-chave: Alzheimer; memória.

\section{Abstract}

This article tries to show that Alzhemier's disease is a medical category which defines senility in a different way from popular notions in Brazil - raising the question about possible consequences for the persons involved. We favour a historical gaze to show how two moments in the history of Alzheimer's disease the "two births" - are the result from the scientific gaze in a certain epoch and its way of producing knowledge.

Key words: Alzheimer; memory.

\section{Introdução}

No Brasil, a doença de Alzheimer como categoria médica se popularizou no início dos anos 90. Antes, havia o que Barry Reisberg escreveu em 1981 para a realidade norteamericana: "É difícil dis-

\footnotetext{
${ }^{1}$ Parte deste texto será publicado em Paradigmas de Atenção Psicossocial, P.G. Delgado (org.), no prelo.

${ }^{2}$ Doutora em Antropologia pela Universidade de Hamburgo, Alemanha. Professora do Instituto de Psiquiatria/UFRJ. Coordenadora geral do Centro para Pessoas com Doença de Alzheimer e Outros Transtornos Mentais na Velhice - CDA. Instituto de Psiquiatria, UFRJ, Rio de Janeiro. 
cutir uma condição para a qual não existe um nome. Realmente, é muito fácil para as pessoas ignorar completamente ou negar a condição para a qual eles nem têm um nome." (itálico meu). Se a doença de Alzheimer é um fenômeno tão recente, às vezes fica difícil acreditar que ela, especialmente nos Estados Unidos, virou uma epidemia, uma das maiores ameaças à saúde pública. Isto, sem dúvida, é ligado também ao crescimento populacional, onde, praticamente no mundo inteiro, o grupo das pessoas acima de 60 anos está aumentando, às vezes de uma forma dramática. No Brasil, tema deste texto, um país popularmente considerado jovem, a faixa etária dos idosos é a que mais cresce em termos proporcionais. Segundo as projeções estatísticas da OMS, entre 1950 e 2025, a população de idosos no país crescerá 16 vezes contra cinco vezes da população total (Silvestre et alii, 1996). Este fenômeno podia ser observado a partir dos anos 50, quando a natalidade baixou significativamente e, ao mesmo tempo, a mortalidade geral (Berquó, 1996). A doença de Alzheimer é ligada à velhice.

Sabemos, porém, que categorias não são "inocentes"; elas não existem fora de seu contexto histórico e local. Elas ajudam a construir realidades, incorporadas em valores, tradições, autoridades e corporalidades. No Brasil urbano, podemos observar como dois princípios de se pensar senilidade - um antigo e um recente estão se encontrando, interagindo de tal forma que lentamente um novo campo semântico está sendo construído.

Senilidade, aqui, refere-se a esquisitices emocionais, comportamentais e/ ou cognitivas, onde a doença de Alzheimer é uma subcategoria que implica em determinadas maneiras de lidar com e entender a pessoa que está envelhecendo.

Favorecemos em seguida um olhar histérico para mostrar o nascimento, ou melhor, os nascimentos de uma categoria que, ao mesmo tempo, revela como definimos e entendemos velhice. Isto porque a doença de Alzheimer virou quase um sinônimo para a velhice, definindo o lado "não-normal" e estruturando e normatizando o que é considerado normal para uma determinada faixa etária. Neste sentido generalizado, Alzheimer significa também a tentativa do homem moderno de lidar com a finitude: por um lado, uma doença pode ser curada - um dia, bem no sentido de Zygmunt Bauman driblando a morte, por outro lado patologizando o que antes fazia parte do envelhecimento (porém 
não necessariamente) revela um mundo em que uma família não é mais multigeracional. Isto é visível, por exemplo, em pequenos apartamentos somente para a família nuclear ou mudanças na estrutura familiar como mulheres fazendo parte do mercado de trabalho de uma forma que não existia antigamente, dificultando o apoio a uma pessoa idosa.

A história da doença de Alzheimer pode ser dividida em fases de glória e as de escuridão, de esquecimento. Talvez seja interessante perguntar aqui, o que teria acontecido entre um "tempo sem nome" e uma "epidemia", ou a invisibilidade e a visibilidade de uma síndrome; uma mudança que pode ser localizada no final dos anos 70 e início dos anos 80 (Leibing, 1997) - visibilidade pública, enquanto a científica já pode ser notada alguns anos antes. É interessante para a nossa análise, também, a mudança do "tempo da descoberta" no início do século para o "período da invisibilidade", poucos anos depois.

Reisberg (1981 p.15), como outros autores, comenta que, somente em 1974, a história da doença de Alzheimer "continuava" - antes, ela estava "medicamente dormindo" (Gubrium, 1986, p.5) - isto 68 anos depois de que Alzheimer - em 1907 - ter publicado o caso da mulher que mostrou os primeiros sintomas demenciais aos 51 anos. Não que não houvesse pesquisadores preocupados com a doença neste intervalo ${ }^{3}$, mas com o olhar de hoje este período não podia existir porque não se encaixava, muitas vezes, no paradigma dominante atual, o "paradígma cognitivo" segundo Berrios (1996), aquele que reduz a demência a funções cognitivas ${ }^{4}$. Toma-se necessário analisar este paradigma ${ }^{5} \mathrm{e}$ as suas conseqüências para a saúde mental dos idosos. E já que um dos mitos sobre a velhice é o declínio cognitivo quase inevitável (Laks,

\footnotetext{
${ }^{3}$ Estudos mais cuidadosos, inclusive o de Reisberg, mencionam publicações no intervalo apontado, mas afirmam que houve uma fase de "latência" até a "renascença" (Bauer, 1994) com o estudo de Newcastle de Roth, Blessed e Tomlinson nos anos 60.

${ }^{4}$ Curiosa, nesse sentido, é uma publicação de Costa Jr., Whitfeld e Stewart, da American Psychological Association (APA), que reunia os abstracts da literatura recente das ciências psicológicas e comportamentais e onde a doença de Alzheimer, na introdução, é definida como "...uma desordem degenerativa progressiva, caracterizada por perda de memória e uma variação de incapacidades cognitivas" (1989, p. VII). A psicologia, nessa publicação, não entra em lugar nenhum.

${ }^{5}$ Mas exato seria chamá-lo de "paradigma cognitivo-cerebral" que não somente descreve um reducionismo em relação aos sintomas, mas também uma limitação do olhar considerando unicamente o cérebro como local da doença de Alzheimer.
} 
1995; Levy e Langer, 1994; Guerreira, 1996), a importância da discussão deste modelo levanta questões também em relação à velhice no mundo ocidental em geral.

Obviamente, não se pode tanto argumentar a favor de um determinismo cultural, quanto também não favorecer o "paradigma cognitivo" - mas uma interação de vários fatores que envolvam o ser humano envelhecendo, ou, como observou Kitwood (1995):

A psiquiatria, no momento, aceita a possibilidade que a explicação [para as prevalências diferentes entre grupos em relação à demência] poderia ser encontrada em fatores ambientais físicos (...) Ir além disso e sugerir que fatores psicológicos e sociais poderiam ser envolvidos na causa da demência, geralmente é proibido. (p. 64)

Mas não foi sempre assim. As vozes de autores como Kitwood (1995), que hoje são tão finas em comparação àquelas dentro do paradigma dominante (embora seja sempre perigoso argumentar em dicotomias que simplificam demais) - já falaram mais altas.

\section{A “descoberta” de Alzheimer}

Podemos mencionar duas correntes de pensamento - entre outras que podem demonstrar o contexto histórico em que a pesquisa de Alzheimer surgiu. Era costume no século XIX reconhecer a demência senil, mas sem contestar a dificuldade de diferenciá-la da senilidade normal ${ }^{6}$. A descoberta de uma forma pré-senil, então, era realmente algo novo. Além disso, Alzheimer desafiava a visão francesa popular, muito ligada à teoria da degeneração, quando mostrou que a demência, por também atingir indivíduos de meia idade, não era somente parte do processo de envelhecimento, mas uma doença específica. Um segundo momento aconteceu na segunda

${ }^{6}$ Charcot, em 1881, por exemplo, concluiu que: “...temos que reconhecer... que as mudanças na textura imprimida no organismo pela velhice, às vezes, ficam tão marcadas que os estados fisiológicos e patológicos parecem se fundir por transições imperceptíveis e não podem ser distinguidos claramente." (apud Berrios, 1990 p. 203) 
metade do século XIX, as (bio-)estatísticas, especialmente depois da Conferência Internacional em 1856, foram consideradas um instrumento valioso para a psiquiatria que até aquele momento somente tinha trabalhado com percentagens. E, segundo Berrios (1990), para poder interpretar corretamente as correlações estatísticas, precisavase de uma matriz conceitual estável em relação à maneira como funções e módulos mentais podiam estar interligados. Ao mesmo tempo, os últimos 30 anos do século passado também foram marcados na psiquiatria por um forte localizacionismo, especialmente depois de Broca (1824 1880). E a partir daí não faltava muito para a noção de que o déficit funcional e a severidade da lesão cerebral podiam covariar e que sua co-variação podia ser considerada como evidência de sua associação (Berrios, 1990, p. 201) - algo que o estudo de New castle iria retomar 100 anos mais tarde.

Vandermeersch, numa publicação recente (1994), aponta para os "mythes d'origine" na psiquiatria, cuja função é a legitimação do presente e que, na maioria das vezes, até persistem, mesmo quando o contrário foi revelado pelos historiadores. Assim, podemos perguntar: por que Alzheimer - já que outros autores antes tinham descrito grande parte dos achados dele e o que ele descobriu afinal?

Nada espetacular, parece, quando se julga pelas três páginas publicadas na Allgemeine Zeitschrift für Psychiatrie und PsychischGerichtliche Medizin, em 1907. O título do artigo, "Sobre um adoecimento estranho no córtex cerebral", apontava para o que Alzheimer não considerava como normal: o processo pré-senil da demência numa mulher de 51 anos. O texto fala sobre os sintomas, primeiro um ciúme exagerado em relação ao marido e depois, ao longo dos 5 anos de sobrevivência, alucinações, amnésia e o que hoje é chamado de apraxia, afasia e agnosia. Depois da morte da mulher aos 56 anos, Alzheimer encontrou no cérebro as placas neuríticas ou senis ("miliare Herdchen") e emaranhados fibrilares típicos. "...Não podemos nos contentar em incluir adoecimentos confusos em categorias clínicas a qualquer custo. Existem, sem dúvida, muito mais doenças mentais de que os nossos livros nos ensinam.", escreveu Alzheimer (1907 p. 148). Por outro lado, ele nunca teve certeza se se tratava aqui de uma doença nova, delimitada, ou de uma sub- 
forma da demência senil.

As placas (ou "Drusen") já foram descritas por Redlich em 1898, o primeiro a relacioná-los à demência senil (antes, em 1892 Blocq; Marinesco já tinham mencionados as placas no cérebro de uma pessoa que sofria de epilepsia) (Bauer, 1994). Também os emaranhados fibrilares relacionados à demência senil já tinham sido descritos antes de Alzheimer por Bianchi; Fuller (Berrios, 1995). Mesmo assim, inicialmente, Alzheimer e seus alunos pensavam que os emaranhados fibrilares eram o marcador da forma présenil, mas logo descobriram que estes também foram encontrados em cérebros idosos. Mais interessante ainda era o achado das placas e emaranhados nos cérebros de pessoas sem demência.

Diferentemente dos colegas, como por exemplo Fischer em 1907 e 1910, que achava que as placas eram patognomônicos, Alzheimer chegou à conclusão de que eles “...não eram a causa da demência senil, mas somente um fenômeno concomitante à involução do sistema nervoso central." (Alzheimer, 1911, apud Bauer, 1994 p.3). Esta frase, "desiludida" segundo Bauer, contribuiu para que as pesquisas em relação à demência do tipo Alzheimer - especialmente após a morte prematura de Alzheimer aos 51 anos, em 1915, ironicamente a mesma idade que sua paciente inicialmente tinha que deu origem à publicação em 1907 - entrassem numa longa fase de "latência" (Bauer 1994, p. 3). ${ }^{7}$

Foi Kraepelin, amigo e colega de Alzheimer, que, na oitava edição de seu Lehrbuch, em 1910, criava o termo "doença de Alzheimer”. No final do século XIX, os cientistas consideravam a demência pré-senil como uma doença da mente (" porque a anatomia não consegue acrescentar nada à psiquiatria", como falou Kraepelin em 1894 para Oskar Vogt, que tinha anunciado a sua intenção de estudar a anatomia cerebral das psicoses (Pollen, 1996 p. 22). Mas esta visão mudou através da visibilidade dos marcadores de senilidade no cérebro, as placas especialmente.

\footnotetext{
${ }^{7}$ Pollen (1996) pensa diferente: “ Olhando para trás, desde o período inicial da descoberta de Alois Alzheimer em 1906 até o meio do século, eu reconheço que não foi por falta de vontade, intelecto ou imaginação que o progresso em relação à doença de Alzheimer foi tão vagaroso. Mas sim por querer técnicas efetivas para aplicar ao problema." (p. 58)
} 
Kraepelin admitia que era difícil separar o envelhecimento normal e os primeiros sinais da demência senil. Mas decidiu, então, nomear a forma pré-senil através do colega dele, embora demonstrasse suas dúvidas:

“A interpretação clínica desta doença de Alzheimer ainda é confusa. Enquanto os achados anatômicos estão sugerindo de que se trata de uma forma especialmente grave da demência senil ${ }^{8}$, o fato de que a doença, às vezes, começa por volta dos 40 anos não permite esta suposição. Neste caso, deveríamos assumir um "senium praecox" ou um processo patológico único, mais ou menos independente da idade." (apud Pollen, 1996 p. 27).

Tudo indica que Alzheimer pretendia mais chamar a atenção para uma forma atípica da demência senil do que criar uma nova entidade. Perusini, um colega italiano, escreveu em 1911, que “...de qualquer forma, embora Alzheimer acredite que estas formas mórbidas [como a doença de Alzheimer] não representem nada senão uma forma atípica da demência senil, (...) seu início extraordinariamente cedo e a forma de sua evolução clínica são suficientes para considerá-los como um grupo separado." (apud Pollen, 1996 p. 28). Outros colegas da época expressaram suas dúvidas sobre a necessidade desta categoria separada da forma senil.

Hoje em dia, Alzheimer é considerado o pai da neuropatologia das demências e Kraepelin a pessoa que reconheceu este mérito cedo. Uma leitura mais cuidadosa, porém, mostra que Alzheimer sempre enfatizava que a patologia no cérebro era um processo secundário a outros fatores desconhecidos. Kraepelin, por exemplo, em 1916, escreveu, que no Altersblödsinn (imbecilidade da velhice) que, como era costume na época, ele ligava à arterioesclerose, resultava de “... abuso de álcool e tabaco, provavelmente também de emoções fortes persistentes [andauernde Gemütsbew egungen] ou cansaço físico [körperliche Überanstren-

\footnotetext{
${ }^{8}$ Este pensamento, de que a forma pré-senil seja mais grave que a senil, sobrevive até hoje. Estados recentes, porém, mostram que as duas forma não diferem entre si na sintomatologia e progresso (Haupt et al., 1993; Tanzi, 1996) 
gungen] e também de opulência na vida. (Kraepelin, 1916, p. 125), o que parcialmente reencontramos nos modelos usados por cuidadores de alguém com a doença de Alzheimer no Rio de Janeiro.

Bleuler, em 1924, se referindo a Kraepelin, repete os fatores patogênicos em relação à forma esclerótica da demência (que, para ele, também resulta de preguiça). A forma pré-senil, a doença de Alzheimer, ele considera como uma forma precoce e muito intensa da presbyophrenia, conceito criado por Kahlbaum. Ele descreve o típico processo degenerativo no cérebro e escreve depois: "As causas ... são desconhecidas.” (p. 299). O fato de Alzheimer ter separado a demência do envelhecimento, o que podia ser interpretado como uma nova entidade psiquiátrica, era decisivo para a sua pesquisa virar um mito de origem no sentido de Vandermeersch - e, sem dúvida, também porque ele era o amigo de Kraepelin, muito influente na época. As descobertas de Alzheimer já "estavam no ar", como mostram as descrições de outros cientistas, p.ex. de Fuller.

O ponto aqui é que a etiologia da demência não era considerada algo meramente orgânico, como hoje, embora a forma precoce e "estranha", fosse provavelmente resultado de processos patológicos no cérebro devido a uma predisposição genética. Esta diferenciação, hoje em dia, raramente está sendo feita pela incorporação da forma senil no termo "doença de Alzheimer", como ainda veremos e, desta forma, abandonando qualquer outro fator sócio-psicológico.

Embora alguns estudos sobre a organicidade da doença de Alzheimer tenham sido feitos depois do primeiro entusiasmo no início do século e antes da "renascença" - Divry e Bouman, por exemplo, trabalharam sobre as placas nos anos 30, como também Gellerstedt ${ }^{9}$ no mesmo período - uma rediscussão da doen-

\footnotetext{
${ }^{9} \mathrm{O}$ artigo de Gellerstedt de 1932/ 33 é interessante por se tratar do primeiro e até hoje provavelmente mais extenso estudo sobre os cérebros de pessoas idosas saudáveis (embora mortas). Destes 50 cérebros, 86\% tinham placas e 78\% mostraram os emaranhados fibrilares e Gellerstedt concluiu que, " ... estas formações, se presentes em pequeno ou grande número, não permite uma afirmação segura sobre o estado mental anterior do paciente." (p. 398) Algo que Perusini já tinha concluído em 1911 e que nega os resultados do estudo de Newcastle, 30 anos mais tarde.
} 
ça e parte do olhar oficial de hoje somente aconteceu nos anos 60. Na França, Delay; Brion (1962), escreveram que "[n]o plano patogênico, os dados são ainda mais obscuros.” (p. 58) e, na página seguinte, sugeriram um processo eventual "hérédo-dégénératif , mas este não bastava para explicar todas as lesões específicas da doença de Alzheimer. O "novo velho olhar", embora inseguro, já estava presente, abrindo o caminho para o "estudo de New castle" onde, a partir de 1966, os pesquisadores britânicos Roth; Blessed; Tomlinson tentaram demonstrar uma relação significativa entre o número das placas e o grau da demência. Com uma amostra não representativa, conseguiram por pouco uma correlação, mas somente porque os autores incluíram um grande número de pessoas sem sinais de demência e sem placas (mais que 40\%) (Bauer, 1994).

Recentemente, em 1993, um dos autores do estudo de New castle, Sir Martin Roth, se distanciou da opinião de que as placas de amilóide tivessem significância importante para a doença de Alzheimer. Mas para nós importa que a partir deste estudo o interesse pelas pesquisas voltaram e que até hoje se concentram na patologia do cérebro, bem como Eisenberg falou: "Desde os meados dos anos 70 a psiquiatria social dos anos 50 'sem cérebro' (brainless), muitas vezes tem sido substituída por uma psiquiatria biológica 'sem mente' (mindless)...” (em Desjarlais et al., 1995).

\section{A "redescoberta” de Alzheimer}

You dont have to be old to join the club.

(Roy Porter, 1995)

Apesar do interesse científico que despertava nos anos 60 o estudo de Roth e colaborad ores, assim como, por exemplo, Terry e colaboradores que através do eletromicroscópio mostraram a participação de microglias no processo patológico no cérebro, ou Gonatas et al. as mudanças nas sinapses dentro das placas - o interesse na velhice como objeto de estudo ainda era pequeno, produto de um preconceito generalizado em relação a esta faixa 
etária (Reisberg, 1981 p. 5). Reisberg mostra que o Comprehensive Textbook of Psychiatry americano de 1666 páginas, no final dos anos 60, dedicava somente meia página a demência senil, doença de Alzheimer e Pick juntos. O livro de neurologia de Merritt (1973), muito usado, não mencionava nenhuma vez em suas 841 páginas a demência senil. Mas entre 1973 e 1975 uma mudança importante ocorreu: embora o livro de Freedman, Kaplan e Sadock agora com 2609 páginas - dedicasse somente duas páginas a demência senil, a doença de Alzheimer agora foi equiparada com esta possibilitando assim a forma relativamente rara da doença de Alzheimer transformar-se na "doenca do século" ou "a maior ameaça para a saúde pública”.

Não era, obviamente, um acontecimento isolado. Novos remédios com efeitos sobre psicose, depressão, mania e ansiedade foram desenvolvidos e para testá-los precisava-se de critérios diagnósticos fiéis, cujo desenvolvimento foi fortemente apoiado pela indústria farmacêutica, mudando cada vez mais para a neurobiologia como local das doenças mentais (Good, 1994). No caso da doença de Alzheimer, os números "apocalípticos" ajudaram a argumentar a favor da "nova" psicopatologia. Realmente, o número dos idosos tem aumentado no mundo inteiro, na média, nos países desenvolvidos, sendo $10 \%$ da população. ${ }^{10}$ Mas a interpretação deste fato vai além de um dado demográfico:

Pessoas idosas constituem 10 por cento da população, mas eles representam 15 por cento dos eleitores... Noventa por cento são registrados para votar e mais de 65 por cento deles votam regularmente. (Butler, 1975, apud Reisberg, 1981 p. 7)

Robert Butler, exagerando e politizando a mudança demográfica, era o primeiro diretor do novo Instituto Nacional do Envelhecimento (National Institute of Aging-NIA), criado em 1974 Butler conta que nos primeiros anos ele encontrava muita hostilidade por colegas médicos de outras áreas, preocupados com o fi-

${ }^{10}$ No Rio de Janeiro, a cidade com o maior número de idosos no Brasil, encontra-se a mesma percentagem (Veras, 1994). 
nanciamento de seus projetos. Por outro lado, o interesse geral em estudos da velhice ainda era pequeno. Butler adotava a "política do medo" (Pollen, 1996) - explicando: "O Congresso não vota a favor de financiamentos para pesquisa básica; eles votam para financiar pesquisas sobre uma determinada doença." (apud Pollen, 1996 p. 80). Ele favoreceu, então, a definição mais inclusiva de Katzman que juntou a forma senil e pré-senil, chamando ambas de "doença de Alzheimer" o que permitiu a ele falar de uma "epidemia" que não afetava somente os idosos - "você poderia ser o próximo" - e que, sem verbas para pesquisa, um dia poderia derrubar a saúde pública com os altos custos. Um movimento que hoje em dia é mundial se iniciou, especialmente também através de organizações leigas de auto-ajuda que com o novo nome podiam dar ordem ao caos, oferecendo um vocabulário para uma experiência sem nome, como escreveu Reisberg. A adoção deste nome incluía um novo campo semântico (Leibing, 1997) - nasceu um novo olhar.

Mas as dúvidas permaneceram - Katzman; Butler sugeriram por não "pré-julgar a identidade etiológica da doença em idades diferentes", chamar a forma pré-senil de "doença de Alzheimer", a forma mais tardia de "demência senil do tipo Alzheimer" (Pollen, 1990). Em textos científicos e populares, porém, ficou "doença de Alzheimer" como nome e protótipo para demência.

\section{Dúvidas e desafios ao paradigma atual}

Von Braunmühl, patologista em Munique, falou em 1932 de uma "crise na morfologia" para a pesquisa da doença de Alzheimer (Bauer, 1994 p. 3) porque os resultados neuropatológicos demonstraram "grandes entrecruzamentos" entre pessoas com e sem demência. Foi nesta época que a psiquiatria em geral estava sendo questionada, como podemos ver, por exemplo, através de uma citação de Adolf Meyer de 1922

“A supermecanização da psiquiatria... [tem] levado para uma confiança grande demais em química efisiologia como 'cura tudo' dos doentes mentais, enquanto a psicanálise, 
por enfatizar demasiadamente o inconsciente e o sexo, tem perdido de vista... as funções da mente consciente e não tem... considerado o fato de que o homem é sujeito à leis físicas... biológicas... e sociais." (apud Eisenberg, 1977, p. ).

O intervalo entre o abandono das descobertas de Alzheimer e a retomada de parte de sua pesquisa nos anos 60, permitia uma visão mais ampla, influenciada pela psicanálise - a doença como envolvendo a pessoa e não somente um processo patológico do cérebro. ${ }^{11}$

O representante mais conhecido deste olhar era David Rothschild que não somente era neuropatologista, como também psiquiatra clínico. Em seu artigo de 1937 sobre as mudanças patológicas na psicose senil, termo usado para a demência senil, e seu significado psicobiológico, ele, como já tinha feito Gellerstedt, chamou a atenção para a incongruência entre a severidade da patologia no cérebro e o grau dos sintomas nos processos mentais. Rothschild supõe que estas diferenças são devidas a habilidades diferentes para compensar das pessoas atingidas. A inabilidade de lidar com problemas pessoais (também Wilson, 1955), especialmente em relação a velhice, poderia ser um dos fatores para a pessoa perder a capacidade de compensar:

"Eu concordo que a diferença entre demência senil e senilidade normal provavelmente tem sua origem na história de vida dos indivíduos." (p. 787)

"Se deveria considerar a pessoa inteira com sua história de vida e suas experiências do dia-a-dia e suas reações frente a estas experiências, especialmente na idade avançada.” (p. 788)

Quatro anos mais tarde, ele publica, junto com Sharp, um artigo onde aponta para a personalidade pré-mórbida e estresse psicológico como fatores adicionais no processo da demência senil:

“... a capacidade da pessoa para compensar o dano [das lesões senis; A.L.] parece ser o fator que determina se uma psicose [senil; A.L.] ocorrerá ou não. Aqui, se tem que contar com características de personalidade, inatas

\footnotetext{
${ }^{11}$ Para críticas a esta época como, p. ex., o caos no diagnóstico ou, muitas vezes a negligência de fatores biológicos envolvidos (Good, 1994, p. 186).
} 
ou adquiridas, que podem ser associadas a uma capacidade fraca..., mas estresse psicológico e esforço excessivo podiam também ter um papel por baixar a resistência do paciente." (Rothschild; Sharp, 1941, p. 53).

Esta visão de que fatores psicológicos influenciam a maneira como compensar os danos cerebrais mudou em 1952 quando a personalidade também passou a ser considerada um fator decisivo para a etiologia da demência: Sands; Rothschild especificam as "características de personalidade", mencionad as anteriormente e descrevem que encontram na personalidade pré-mórbida de seus pacientes um número significante de pessoas que tendem a ser mais rígidas e dependentes - resultados que Bauer, em 1994, também encontra em sua amostra alemã. ${ }^{12}$

Interessante nesta discussão é que, para Rothschild, tanto fatores biológicos como também outros fatores "de uma natureza mais pessoal" (1937) - os estresses da vida e como estes são enfrentados por cada um - são envolvidos no processo demencial, em interação e interdependentes. ${ }^{13}$

\section{E a Rita Hayworth?}

Os contextos mudam e com eles a maneira como entendemos o mundo. Por isso, não se trata aqui de um mero interesse histórico, dados curiosos, porque paradigmas não são entidades delimitadas - quando um começa, o outro acabou. Podemos reencontrar constantemente a visão de Rothschild e seus colegas no discurso não-profissional ${ }^{14}$ atual - tanto nos Estad os Unidos quanto

\footnotetext{
${ }^{12}$ A "renascença" do paradigma como era representado por Rothschild, pode ser observado também no campo acadêmico "alternativo" atual, veja Leibing, 1997.

${ }^{13} \mathrm{O}$ paradigma atual dominante também parte de uma etiologia multifatorial, mas dentro de um pensamento mecânico, o que Kitwood (1988) chamou de "the technical frame". P. ex, fatores socio-culturais somente são considerados, como no caso da educação, na medida em que esta estrutura as conexões sinápticas, a chamada "reserva cerebral” : " [Mortimer] tem a hipótese de que fatores psicossociais têm a sua associação mais forte na DAT senil [demência do tipo Alzheimer de severidade leve e moderada e... que uma inteligência baixa pré-mórbida acelera o diagnóstico clínico da DAT.' (...) [A] descoberta recente de que um relacionamento forte existente entre a densidade sináptica neocortical e o declínio cognitivo na doença de Alzheimer oferece um stratum biológico para a postulada 'reserva intelectual' " (Katzman, 1993, p. 13)

${ }^{14}$ Numa pesquisa em andamento no Instituto de Psiquiatria - IPUB/UFRJ, podemos observar o "outro" paradigma também em profissionais que trabalham menos dentro do paradigma dominante.
} 
no Brasil, embora com conotações diferentes.

Não é a minha intenção jogar o "saber popular" contra o "profissional" como uma subcategoria, menos válida ou romantizada, mas chamar a atenção para o que Foucault (1994) denominou de "saber subjugado", aquele que foi "... desqualificado como inadequado...: saberes ingênuos, localizados baixos nas hierarquias, embaixo do nível de cognição [!] ou cientificidade." (p. 41) Estes savoirs des gens, como os chama Foucault, não são “... em primeiro lugar opostos aos conteúdos, métodos ou conceitos de uma ciência”, mas "aos efeitos dos poderes centralizadores que estão conectados às instituições e funcionamento de um discurso científico organizado dentro de uma sociedade como a nossa”. (p. 43)

A história de Rita Hayw orth poderia ser considerada como "paradigmática" para a cultura pública norteamericana: Rita Hayworth (1918-1987), símbolo de beleza, juventude e glamour hollywoodiano, hoje em dia virou símbolo da campanha da Associação de Alzheimer norteamericana, promovida por sua filha, princesa Yasmin Aga Khan. Numa entrevista, dada ao jornal Washington Post (1204 1989), Yasmin de 40 anos olha para trás:

"Foi o ímpeto em suas emoções. Ela ficava com raiva de repente. Nem posso lhe contar. Pensei que era alcoolismo - demência alcóolica. Todos nós pensamos isto. Os jornais usaram isto, claro. Você não pode imaginar o alívio somente por ganhar o diagnóstico. Finalmente, tivemos um nome, Alzheimer's!... Ela não foi diagnosticada até 1980. Foram duas décadas de inferno antes.

"Foram tantas coisas pequenas, no início. Isto é, olhando para trás. Ela arrastava os pés. Ela brincava (fiddle) com suas mãos. Ela ia ficar tão incrivelmente agitada. A paranóia, as mudanças de humor, os comportamentos esquisitos. Algo em seu olhar. Acho que dá para notar em "Separate Tables". Ela reorganizava seu guarda-roupa, obsessivamente, toda hora. Eu ficava me perguntando como as roupas dela chegaram no meu guarda-roupa. Eu era somente uma menina. Era quase engraçado. Agora posso olhar para trás e tudo se conecta. (...) 
"Até no auge de sua carreira, Rita Hayworth já mostrava sinais sutis da doença que mais tarde ia aleijar sua mente, disse sua filha."

O conceito de pessoa demente aqui apresentado se distingue da versão brasileira. Nos Estados Unidos, a pessoa através da doença, que é vista como "algo", "uma semente que cresce", desencadeia um processo para um estado de não-pessoa. Numa outra reportagem de 1983 (em Gubrium, 1986, p. 138), grande parte da vida de Rita é vista como "não sendo realmente ela", mas a doença determinando os seus atos e sentimentos:

"Se, como suspeita Yasmin, Rita começou a sofrer de Alzheimer algo como 25 anos atrás, isto explicaria muita coisa sobre sua vida pessoal díficil. Embora ela tivesse tido muitos relacionamentos complicados durante sua vida, suas dificuldades parecem ter aumentados depois de seu divórcio de Aly Khan. (...) Em retrospectiva, seria muito possível que por causa de Alzheimer ela começou a não saber escolher os seus amigos com sabedoria."

Este "algo" que não se sabe o que é, mas, pelo menos, agora tem um nome, no Brasil poderia ser considerado como "relacional", porque Alzheimer no discurso não-profissional é resultado de uma vida dura, de muito trabalho e uma personalidade forte e ao mesmo tempo fechada - um processo que lembra Rothschild e colaboradores. Sem entrar em detalhes (Leibing, 1997), o que interessa aqui é que o modelo "relacional" está começando a ser coberto por uma visão mais mecanicista devido a um maior conhecimento sobre a doença de Alzheimer. ${ }^{15}$ Em virtude do pouco tempo o qual esta síndrome está ganhando popularidade na mídia no Brasil, desde o início dos anos 90, os dois modelos foram apresentados, muitas vezes, paralelamente em nossas entrevistas, algo raro em nosso mundo globalizado onde sistemas de referências são cada vez mais interligados, com fronteiras permeáveis e imprevisíveis (Bibeau, 1997). As entrevistas realizadas por nós - longe de serem "nativos" ou "étnicos" - mostram, provavel-

${ }^{15}$ A maioria das pessoas entrevistadas eram da classe média carioca. 
mente por pouco tempo, um corte sincrônico onde se consegue ainda distinguir com mais clareza o encontro de um referencial "mecanicista" e um centrado na pessoa ou "relacional".

Interessante é que, no Brasil, o modelo biomédico, especialmente o genético, tem mais peso quando a pessoa em questão era uma pessoa feliz durante a sua vida; o valor explicativo do modelo "relacional" era menor, neste caso. Uma pessoa que teve uma vida sofrida, dura, se desgastava, especialmente quando era "fechada" emocionalmente, não tendo a possibilidade de desabafar, princípio ancorado na patologia humoral, podia ser entendida como sofrendo de Alzheimer.

Quatro exemplos:

"É isto que estou me perguntando. Do ponto de vista médico, foram um número de fatores, mas eu acho que depende - o que eu sei é que a minha mãe teve uma vida muito dura. Meus avós morreram cedo, uma madrinha a pegou e logo depois também faleceu. Ela foi mandada para um orfanato.

"Talvez porque ele se preocupou demais com seu trabalho. Meu pai trabalhava demais em sua loja, mas, claro, não foi somente isto. Seu temperamento era muito forte; ele se preocupou, mas não se pode dizer que a causa de Azheimer somente é preocupação na vida. Não se sabe ainda as causas concretas, mas eu acho que é porque ele teve muitas preocupações na vida, isto é o que contribuiu para a doença.

"Acho que é um problema genético, mas o que eu sei é que estas doenças são pouco conhecidas... Talvez ela se distanciando cada vez mais iniciou a doença, não tenho certeza. Minha mãe morava longe de seus parentes, no subúrbio, sem telefone, com meu pai. Sua irmã mais querida morreu. Nenhuma atividade como trabalho ou ir para o banco.

"Leio muito sobre tudo, sei do cromossomo 21 e tudo isso. Mas acho que a insatisfação, a tristeza, o estresse e o fechamento em um mundo cada vez menor podem ajudar muito para a auto-destruição. Minha mãe ficou viúva com 27 anos. Viveu para filhos, netos, depois a mãe dela..." 
A negociação entre um "se não sabe", "genético" ou "pouco conhecido" e o resultado de uma vida desgastante pode ser percebido nestas narrativas. Ao contrário do exemplo norteamericano, onde a partir de um determinado momento a doença se manifesta inicialmente despercebida, mas, olhando para trás, já não se tratava mais da pessoa em sua verdadeira essência, ela virava não-pessoa - no Brasil, a pessoa, muitas vezes com admiração, é descrita como vítima de uma vida em que batalhou e onde a impossibilidade de lidar com as fortes emoções e o desgaste tiveram um resultado dramático.

\section{Conclusões}

Por que precisamos saber tudo isto? Afinal, não podemos fazer nada, já que a doença Alzheimer é irreversível. Uma psiquiatria "ateórica e descritiva" não contextualiza. Um modelo que leva em consideração a história de vida, doença como resultado de um processo vivido, também consegue ver a pessoa dentro do processo demencial - embora tristemente incapacitada. Neste aspecto, existem também diferenças, visões até contrárias (p. ex., Rita Hayw orth vs. os exemplos brasileiros) - principalmente, como a história de vida se refere ao mundo referencial.

Young (1980), num contexto parecido, falando sobre o discurso do estresse, adverte para o perigo que este “... é um discurso social - alega situar a patogênese dentro da experiência do dia-adia - sua especificidade tem conseqüências ideológicas importantes no sentido de legitimizar a ord em social existente." (p. 144) A individualização do sofrimento de Rita Hayworth poderia ser pensado desta maneira.

O exemplo brasileiro contém, porém, um elemento mais "subversivo" (Bibeau, 1997). Se a vida é considerada como potencialmente patogênica - "a vida é combate que os fracos abate..." podemo-nos perguntar, 'que vida é essa? ${ }^{16}$

\footnotetext{
${ }^{16}$ Veras; Murphy (1994), infelizmente sem aprofundar mais o seu pensamento, chegam a conclusão que “... pode ser que [no Brasil] realmente há significativamente mais demência na população idosa ... dos quais muitos viviam uma vida em circunstâncias de dificuldades [hardship] excepcionais." (p. 291)
} 


\section{Referências bibliográficas}

1 ALZHEIMER, A. Über eine eigenartige Erkrankung der Hirnrinde, Allg. Zeitschrift für Psychiatrie und Psychisch-GerichtlicheMedizin, v.64, p. 146-148, 1907.

2 BAUER, J. DieAlzheimer-Krankheit, Neurobiologie, Psychosomatik, Diagnostik und Therapie. Stuttgart Schattauer, 1994

3 BERRIOS, G. E. Cognitive Impairment, In: THE HISTORY of Mental Symptoms, Descriptive Psychopathology since the Nineteenth Century. Cambridge, Cambridge University Press, 1996, p. 172-207.

4 MEMORY and the Cognitive Paradigm of Dementia during the 19th Century: a conceptual history, In: MURRAY, R. M.; TURNER, T. H. (Eds.) Lectures on the History of Psychiatry, London, The Royal College of Psychiatrists, 1990, p. 194211.

5 DEMENTIA During the Seventeenth and Eighteenth Centuries: a conceptual history. Psychological Medicine, 17, p. 829-827, 1987.

6 BIBEAU, G. Cultural Psychiatry in a Creolizing World: questions for a new research agenda. Transcultural Psychiatry. v. 34, n. 1, p. 9-41, 1997.

7 BLEULER, E. Textbook of Psychiatry. New York, The Macmillian Co, 1924

8 BUTLER, R. H. Foreword. In. BINSTOCK, R. H.; POST, S.; WHITEHOUSE, P. J. (Eds.). Dementia and Aging, Ethics, Values and Political Choices. Baltimore, Johns Hophins University Press, 1992 p. VII-IX.

9 COSTA Jr, P. T.; WHITFELD, J. R.; STEWART, D. Alzheimer's Disease: Abstracts of thePsychological and Behavioral Literature. Hyattsville, APA, 1989.

10 DELAY, J. S. Brion Les Démences Tardive. Paris, Masson \& Cie, 1962

11 DESJARLAIS, R.; EISENBERG, L.; GOOD, B.; KLEINMANL, A. A World Mental Health Report, Problems and Priorities in Low- Income Countries. New York, Oxford University Press, 1995.

12 EISENBERG, L. Development as a Unifying Concept in Psychiatry. Brit. J. Psychiatry, v. 131, p. 225-237, 1977.

13 C. I.; E. A. Binney. The Biomedicalization of Aging: dangers and Dilemmas. In: MINKLER, M.; ESTES, C. L. (Eds.), Critical Perspectives on Aging, The Political and Moral Economy of Growing Old, New York: Bayw ood, 1991, p. 117- 134 
14 FINGER, S. Origins of Neuroscience, A History of Explorations into Brain Function, New York/ Oxford, Oxford University Press. 1994

15 FOUCAULT, M. Genealogy and Social Criticism. In: SEIDMAN, S. (Ed.), ThePostmodern Turn, New Perspectives on Social Theory. Cambridge, Cambridge University Press, 1994 p.39-45.

16 GELLERSTEDT, N. Zur Kenntnis der Hirnveränderungen bei der normalen Altersinvolution. Upsala Läkareförenings Förhandlingarv. 5, n. 6, p. 193-408, 1933.

17 GOOD, B. J. Culture and Psychopathology: directions for Psychiatric Anthropology. In: SCHWARTZ, T.; WHITE, G. M.; LUTZ, C. A. (Eds.), New Directions in Psychological Anthropology. Cambridge, Cambridge University Press, 1994, p. 181-205.

18 GUBRIUM, J. F. Oldtimers and Alzheimer's: the descriptive organization of senility. Greenwich, Jai Press, 1986.

19 HAUPT, M.; POLLMANN, S. Kurz. Symptom Progression in Alzheimer's Disease: relation to onset age and familial aggregation. Acta Neurol Scand, v. 88, n. 5, p. 349-353, 1993.

20 HENDERSON, J. N. Mental Disorders Among the Eld erly, Dementia and its Sociocultural Correlates, In: SIILVERMAN, P. (Ed.) The Elderly as Modern Pioneers. Bloomington, Indiana University Press, 1987. p. 57-374.

21 KATZMAN, R. Education and the Prevalence of Dementia and Alzheimer's Disease. Neurology, v. 43, p. 13-20, 1993.

22 KITWOOD, T. Dementia, Social Section II, In: A History of Clinical Psychiatry, The Origin and History of Psychiatric Disorders. New York, New York University Press, 1995. p. 1995.

23 THE TECHNICAL, the Personal, and the Framing of Dementia. Social Behaviour, v. 3, p. 161-179, 1988.

24 KRAEPELIN, E. Einführung in diePsychiatrischeKlinik Arteriosklerose und Altersblödsinn. Einführung in die Psychiatrische Klinik, $3^{\mathrm{a}}$ ed. Leipzig, Verlag von J. A. Barth, 1916.

25 LAKS, J. O que há de mais em ter 65anos? JBras Psiquiatria, v. 44, n. 7, p. 255-260, 1995.

26 LEIBING, A. Narrow ing Worlds: On Alzheimer's Disease and biography in Brazil, In: LEIBING, A. (Ed.) The Medical Anthropologies in Brazil, Berlim, VWB-Verlag, 1997. 
27 PORTER, Roy. Dementia, Social Section. In: A History of Clinical Psychiatry: theorigin and history of psychiatric disorders. New York, New York University Press, 1995. p. 52-62

28 REISBERG, B. A GuidetoAlzheimer's Disease. New York, The Free Press, 1981.

29 ROTHSCHILD, D. Pathological Changes in Senile Psychoses and their Psychobiological Significance. Am J. Psych, v. 93p. 757-788, 1937.

30 ROTHSCHILD, D.; SHARP, M. L. The Origin of Senile Psychoses: Neuropathologic Factors and Factors of a More Personal Nature. Diseases of the Nervous System, v. 2 n. 1, p. 49-54, 1941.

31 SANDS, S. L; D. Rothschild Sociopsychiatric Foundations for a Theory of the Reactions to Aging, JNervous and Mental Diseases, v. 116, p. 233-241, 1952

32 STAFFORD, P. B. The Social Construction of Alzheimer's Disease. In: SEBEOK; UMIKER-SEBEOK, J. (Eds.) Biosemiotics, the Semiotic Web 1991. Berlin/New York, Mouton de Gruyter, 1992 p. 393-406.

33 TANZI, R. Informação via Internet, 1996.

34 VANDERMEERSCH, P. Les mythes d'originein the History of Psychiatry, In: MICALE, M. S.; PORTER, R. (Eds.). Discovering the History of Psychiatry, New York/ Oxford, Oxford University Press, 1994, p. 219-231.

35 VERAS, R. País Jovem com Cabelos Brancos. A Saúde do Idoso no Brasil, Rio de Janeiro, Relume Dumará, 1994

36 VERAS, R. P.; Murphy, E. The Mental Health of Old er People. Intern J Geriatric Psychiatry, v. 9, p. 285-295, 1994

37 HENDRICKSON, P. Tales of Pain for a Star' Daughter, Alzheimer's ruined Rita Hayw orth, 1989. P. b3.

38 WILSON, D. C. The Pathology of Senility. Am JPsych, v. 111, p. 902-906, 1955.

39 YOUNG, A. The Discourse on Stress and Reproduction of Conventional Knowledge. Social Scienceand Medicine, v. 14b, p. 133-146, 1980. 